Recebido:

06.05.12

Aprovado:

11.11.12

1. Doutor em Ciências Sociais e professor adjunto da Unidade Acadêmica de Ciências e Tecnologia Ambiental da Universidade Federal de Campina Grande. E-mail: robertosmiranda@ yahoo.com.br

\section{Ecologia política e processos de territorialização}

Roberto de Sousa Miranda ${ }^{1}$

Resumo: Propõe-se uma Ecologia Política que complemente a noção de projetos territoriais, apreendidos pela análise das disputas entre diferentes estratégias políticas orientadas por atividades econômicas que articulam atores e ambientes, e possibilite a análise dos conflitos e dos processos de mudança ambiental. O estudo dos conflitos socioambientais deve partir da análise intensiva de casos históricos, a fim de elucidar como os atores sociais em disputa estão ligados entre si por modos específicos de dependência recíproca, pautados num equilíbrio móvel de tensões, que resultam em processos de territorialização, compreendidos enquanto transformações nas formas de apropriação do território e seus recursos naturais, que são constantemente estruturadas, desestruturadas e reestruturadas pelas práticas dos grupos sociais e pelas relações de interdependência estabelecidas, que os ligam uns aos outros pelas redes de interesses referentes à figuração social.

Palavras-chave: Ecologia Política, Conflitos socioambientais, Figurações sociais, Processos de territorialização.

Abstract: It is proposed a political ecology that complements the notion of territorial projects, apprehended by the analysis of disputes among different political strategies conducted by economic activities that articulate social actors and environments, it enables the analysis of conflicts and processes of environmental change. The study of socio-environmental conflicts should come from intensive analysis of historical cases in order to elucidate how social actors in dispute are bound together by specific modes of mutual dependence, interlined by a moving equilibrium of tensions, which result in territorialization processes, understood as transformations in the forms of appropriation of territory and their natural resources, which are constantly structured, unstructured and restructured by the practices of social groups and the established interdependent relationships, that bind them to each other by networks of interests relating to social figuration.

Keywords: Political ecology, Socio-environmental, Social figurations, Territorialization processes.

Introdução

nquanto campo de pesquisa, a Ecologia Política combina perspectivas: da Ecologia Humana, inter-relações que as sociedades mantêm com os ambientes em que habitam (LITTLE, 2006); da Econo- 
mia Política, o foco nas relações estruturais de poder entre sociedades; e da Ecologia Cultural, em relação às adaptações dos indivíduos ao meio ambiente (CUNHA, 2004). A inserção da economia política trouxe à tona o impacto dos sistemas produtivos nas mudanças socioambientais e a importância das relações de poder na determinação do acesso e uso dos recursos naturais (BIERSACK, 1999).

Os trabalhos orientados pela Ecologia Política têm tratado de quatro temas principais: (1) a ideia de que a utilização dos recursos naturais é organizada por relações sociais que pressionam o meio ambiente; (2) o reconhecimento da pluralidade de posições, interesses e racionalidades sobre o ambiente, de modo que o lucro de uma pessoa pode representar a pobreza de outra; (3) a ideia de uma conexão global por meio da qual os processos políticos e econômicos externos estruturem e sejam influenciados pelas questões locais; e (4) a defesa de que a degradação da terra é um resultado e uma causa da exclusão social (GEZON e PAULSON, 2004).

Os maiores avanços no campo de pesquisa da Ecologia Política deram-se em disciplinas como a Economia Política, a Antropologia e a Geografia, as quais pautaram fortemente as agendas de pesquisa e os instrumentos teóricos e metodológicos. Na Sociologia, essa abordagem tem tido menor atenção, ainda que possa contribuir fortemente para seu aprimoramento, em particular no debate sobre o poder enquanto variável explicativa dos conflitos e dos processos de mudança ambiental, cada vez mais presente (MIRANDA, 2011).

A fim de superar essa lacuna, realizo o esforço de incorporar criativa e não dogmaticamente a abordagem de Norbert Elias sobre o poder, por meio da utilização da ideia de figurações sociais, para pensar as relações no interior dos grupos sociais e entre estes, em nível local, regional, nacional e até mesmo global. Procedimento esse que servirá como alternativa às conceituações de poder, de inspiração marxista, com foco mais estrutural em diferenças de classe ou na dinâmica capitalista, muito influente na Ecologia Política dos anos de 1980.

As estratégias utilizadas para o fiel cumprimento do objetivo deste artigo partem de uma revisão bibliográfica representativa da Ecologia Política, para mostrar que a Sociologia, a partir de Norbert Elias, tem muito a contribuir para o ressignificação do conceito de poder. A incorporação da ideia de interdependência e de figurações sociais fornece as condições para o casamento entre Ecologia e Política, enquanto aspectos centrais para o entendimento dos conflitos e processos de mudanças ambientais ligados à apropriação do espaço e seus recursos.

O conceito de poder em Elias $(2001 ; 2005)$ alicerça-se no pressuposto de que as sociedades são figurações de indivíduos interdependentes, que refletem equi- 
líbrios de tensões, mesmo nos casos em que as diferenças de poder entre os grupos que compõem a figuração social sejam grandes. As mudanças numa figuração social, por sua vez, ocorrem à medida que são alteradas as relações globais de interdependência funcional, o que induz os grupos sociais a contestar o poder de coerção do outro grupo e, assim, redefinir as estruturas de poder.

Uma figuração social representa uma teia de inter-relações que se aplica:

(...) tanto a grupos relativamente pequenos como sociedades constituídas por milhares ou milhões de pessoas interdependentes. Professores e alunos numa aula, médico e doentes num grupo terapêutico, clientes habituais num bar, crianças num infantário - todos eles constituem configurações relativamente compreensíveis. (ELIAS, 2005, p. 143)

O conceito de figuração expressa claramente e inequivocamente o que chamamos de sociedade, ao expressar as redes de interdependência que ligam e tornam os seres humanos mutuamente orientados (ELIAS, 1994), servindo, portanto, "de simples instrumento conceptual que tem em vista afrouxar o constrangimento social de falarmos e pensarmos como se o «indivíduo» e a «sociedade» fossem antagónicos e diferentes" (ELIAS, 2005, p. 141).

A análise das ações de grupos sociais que interagem por meio de discursos e estratégias que procuram legitimar e institucionalizar processos de regulação, acesso e uso de recursos naturais pode ser aprendida mediante a distinção de dois tipos de interdependência, uma que liga os membros do grupo e articula suas ações e outra que conecta todos os grupos que defendem diferentes projetos de apropriação e uso dos recursos naturais (MIRANDA, 2011).

As figurações sociais possibilitam a análise dos processos de apropriação de recursos naturais enquanto projetos territoriais, que são as estratégias políticas que envolvem atores e instituições sociais que tentam legitimar e/ou institucionalizar modelos de regulação, de acesso e de uso desses recursos. Para compreender as tensões entre os diferentes projetos territoriais, numa figuração específica, e se distanciar das propostas pautadas na descontinuidade e unilateralidade, uso o conceito de processos de territorialização (CUNHA, SILVA e NUNES, 2008).

A Ecologia Política aqui proposta, portanto, parte da ideia de que mudança ambiental e os processos de territorialização são equivalentes, pois refletem transformações nas relações entre sociedades e naturezas. A diferença entre as duas categorias analíticas é que os processos de mudança ambiental focalizam as transformações ambientais provocadas pelas práticas dos atores sociais, ao 
passo que os processos de territorialização centram-se no entrelaçamento das práticas dos atores sociais e seus efeitos sobre o espaço ${ }^{2}$ (CUNHA, SILVA e NUNES, 2008).

\section{Conflitos e mudanças socioambientais}

A Ecologia Política surge em reação a determinadas características da Ecologia Humana ou Antropologia Ecológica, praticada nos anos 1960 e início dos anos 1970, que negligenciavam as dimensões políticas das interações entre seres humanos e o meio ambiente; preocupavam-se com os processos de adaptação (VAYDA e WALTERS, 1999). Ao passar dos anos, a abordagem desdobrou-se em duas orientações principais: (1) a Ecologia Política normativa, que defende a preservação do meio ambiente e a justiça social, e (2) a Ecologia Política analítica, que realiza um esforço teórico-metodológico para analisar os conflitos e as mudanças socioambientais.

Para os ecologistas políticos normativos, os conflitos associados à apropriação de recursos naturais ${ }^{3}$ refletem sobre a atuação de intelectuais e do movimento trabalhista na defesa ambiental (LIPIETZ, 2003), na cultura e na identidade locais (ESCOBAR, 2005; LEFF, 2003), na expansão do ecologismo ou ambientalismo em reação ao crescimento econômico (ALIER, 2007) e na discussão da relação entre riscos à saúde e ao ambiente (PORTO, 2007). Apesar de tratar de diferentes aspectos, a Ecologia Política normativa é perpassada pela tentativa de difusão da preservação da natureza e pela garantia de acesso aos recursos naturais às gerações futuras.

Advogado da Ecologia Política normativa, Lipietz (2003) ressalta que a abordagem representa o movimento sociopolítico com melhores condições de transformar a realidade por meio de análises teóricas, militâncias e luta política. Ou vislumbra-se, como sugere Escobar (2005), a possibilidade de reintrodução do local nas discussões relativas à globalização, ao permitir a incorporação de práticas econômicas orientadas pelo contexto local em que as comunidades estão inseridas, ou seja, trata-se de uma valorização da cultura local.

Na verdade, Escobar (2005) propõe uma Ecologia Política que, articulada pelos movimentos sociais, defenderia a identidade, o lugar e a região. A construção dessa argumentação baseia-se no confronto de forças e discursos nacionais e transnacionais que tratam da exploração de minérios e de madeira e do avanço da agroindústria, com discursos de preservação do meio ambiente e de decomposição e recomposição de identidades locais e regionais. O esforço do autor em repensar as relações entre o local e o global é pertinente, mas a sua tentativa de redefinir práticas políticas e ambientais acaba separando a política da natureza,
2. O espaço contempla simultaneamente o ambiente físico e as relações sociais (CABRAL, 2007). O que, segundo Santos (1999), implica dizer que o espaço é a síntese provisória do conteúdo social e das formas espaciais. A partir do momento que o espaço é apropriado pelos atores sociais, concreta ou simbolicamente, ele torna-se um território, expressando assim, as relações de poder que referenciam o controle e a gestão do espaço (RAFFESTIN, 1993).

3. Hardin (1968) explora a relação entre crescimento populacional e o uso de recursos naturais, a partir do exemplo das pastagens coletivas, para nos mostrar que a maximização de benefícios e a redução de custos podem ocasionar a degradação ambiental, que seria evitada com a privatização ou estatização dos recursos naturais. Hardin foi criticado por confundir acesso livre com propriedade comum, em que o acesso e uso de recursos naturais são regulados por normas sociais (KLINK, 1992; CUNHA, 2002). Ostrom (1990, 1994, 1998), por exemplo, demonstra empiricamente que as propriedades $\mathrm{CO}$ muns, com floresta e estoques pesqueiros, são geridas com 
sucesso pelos próprios usuários.

4. O desaparecimento do campesinato em virtude do processo de desenvolvimento industrial e tecnológico, não é uma questão nova, foi levanta por Karl Kautsky, no final do século XIX, no livro $A$ questão agrária. conforme destaca Latour (2004).

\section{Conflitos socioambientais: o caso das quebradeiras de coco babaçu}

Na década de 1970, as políticas e programas governamentais voltados para a modernização da agricultura e de povoamento tornaram-se vetores de conflitos associados à apropriação de recursos naturais. Nos estados do Piauí, Maranhão, Tocantins e Pará, os conflitos entre quebradeiras de coco, que dependem da extração e comercialização do coco babaçu e da pequena agricultura, e grandes fazendeiros emergiram a partir da implementação de grandes projetos agropecuários na região (MEDEIROS, 1996).

Nas áreas de coleta do coco babaçu, os programas de estímulo à atividade pecuária, fomentados pelos governos estaduais e federais, levaram à expropriação das terras dos pequenos produtores; ao cercamento e/ou derrubada das palmeiras, o que impediu o trabalho de coleta; e à transformação das relações de produção, pois alguns proprietários passaram a cobrar taxas ou exigir a preferência de compra do babaçu coletado, tornando-se atravessadores (MEDEIROS, 1996).

A estratégia adotada pelas quebradeiras de coco babaçu para vencer as dificuldades foi a cooperação, mediante a criação de associações de quebradeiras e do Movimento Interestadual das Quebradeiras de Coco Babaçu (MIQCB), que politizou a definição quebradeiras de coco. Houve também a organização de cooperativas para comercializarem as amêndoas de babaçu e evitarem os atravessadores, que muitas vezes são os proprietários das terras (MEDEIROS, 1996).

Outra questão que vem sendo muito debatida pelos ecologistas políticos normativos é a luta pela manutenção da biodiversidade, que tem como pano de fundo as novas dimensões dos conflitos socioambientais, marcados pelo desenvolvimento técnico-científico (biogenéticos, transgênicos, por exemplo) para a apropriação dos recursos naturais, o que leva a uma nova forma de biopolítica, orientada pelo controle e apropriação dos recursos, que acabam beneficiando os países ricos e fragilizando mais os países pobres (GÖRG e BRAND, 2000; GARI, 2000; BELMONTE, 2004).

Algumas das novas biotecnologias agrícolas estão supondo, na prática, o desaparecimento do camponês ${ }^{4}$, das pequenas e médias empresas de sementes e das empresas tradicionais dedicadas ao processamento de alimentos. A biotecnologia está presente na agricultura há certo tempo (BELMONTE, 2004); contudo, as novas biotecnologias modificaram os protagonistas históricos do processo, camponeses e pecuaristas, que lutam para ter acesso aos recursos naturais controlados pelos laboratórios e empresas transnacionais (WALKER, 2011). 
Uma análise crítica da Ecologia Política normativa, a partir de Vayda e Walters (1999), mostra-nos que, na maioria dos casos, essa vertente coloca a prática de pesquisa a serviço de uma ordem política populista, um romanticismo verde, de pensar que, devolvendo o controle dos recursos naturais para as comunidades locais, mitigar-se-iam as influências do sistema político-econômico e tornar-se-ia sustentável o uso dos recursos naturais. Não há, portanto, uma preocupação com o debate teórico sobre os conflitos e os processos de mudança ambiental, mas uma militância ambientalista.

Segundo Vayda e Walters (1999), a Ecologia Política é uma alternativa à Ecologia sem política. A Ecologia sem política dos anos 1960 transformou-se numa Política sem ecologia, nos anos 1990, que se apresentou como Ecologia Política, em vez de políticas de recursos naturais, Antropologia Política ou Ciência Política. Os pretensos ecologistas políticos estudavam os controles ou competições políticas sobre o uso dos recursos naturais, deixando, assim, de abordar o modo como os recursos naturais são afetados pelos controles e competições políticas.

Se o objeto de estudo é a mudança ambiental, uma alternativa programática à Ecologia Política, para Vayda e Walters (1999), seria a evenemental ou event ecology. O foco da pesquisa passa a ser os eventos ambientais, analisados no tempo e no espaço exterior pregressos, de modo que sejam reconstruídas as causas e os efeitos desses eventos ou mudanças. Evita-se, assim, a prática de concentrar a investigação no acesso aos recursos naturais ou na mudança do acesso, que dá pouca ou nenhuma atenção às questões socioambientais que de fato devem ser tratadas.

A Ecologia de evento tem a pesquisa guiada por perguntas abertas, por exemplo, por que as mudanças socioambientais acontecem? Vayda e Walters (1999) criticam os ecologistas políticos que privilegiam os eventos políticos e econômicos em vez de analisar como estes podem ser causas importantes de mudanças ambientais; e os que analisam eventos políticos, como o acesso a recursos naturais, e usam os dados de pesquisa para fazer reivindicações políticas e ambientais.

A Ecologia de evento, enquanto alternativa à Ecologia Política, oferece duas vantagens: (1) diminui a probabilidade de conclusões equivocadas fundamentadas em bases teóricas preconcebidas (por exemplo, mudança e degradação ambientais podem ser causadas por ricos e pobres); e (2) não prejulga os fatores políticos para eleger qual destes é o mais importante de antemão. Todos os eventos políticos devem ser considerados da mesma maneira que os fatores biofísicos o são para explicar as mudanças ambientais (VAYDA e WALTERS, 1999).

A proposta de Vayda e Walters (1999) representa um esforço teórico de se repensar a Ecologia Política, sem negligenciar o seu foco principal, a partir de um 
5. Dentre os principais programas, destacam-se: o Programa de Assentamento Dirigido do Alto Parnaíba (PADAP), criado em 1971; o Programa de Cooperação Nipo-Brasileiro para o Desenvolvimento dos Cerrados (PRODECER), iniciado em 1974; e o Programa de Desenvolvimento dos Cerrados (POLOCENTRO), criado em 1975.

6. Os programas de maior impacto para a Amazônia Legal foram: o Plano de Integração Nacional (PIN), criado em 1970; o Programa de Pólos Agropecuários e Agrominerais da Amazônia (POLAMAZÔNIA), criado em 1974; e o Programa Grande Carajás (PGC), iniciado em 1980. alerta para os equívocos analíticos decorrentes da dissociação entre conflitos e processos de mudança socioambiental. Porém, a event ecology possui duas limitações: (1) não fica claro como os eventos ou mudanças ambientais locais podem estar associados a questões políticas e econômicas regionais, nacionais ou internacionais; e (2) a definição de eventos utilizada encobre as inter-relações existentes entre os diferentes atores e grupos sociais envolvidos em conflitos e mudanças socioambientais.

As diferentes teses apresentadas acima representam o desenvolvimento da Ecologia Política e de seu campo de pesquisa. Trata-se de trabalhos que articulam mudança ambiental e marginalização emergem primeiro nos anos 1970 e 1980, como uma tentativa de aplicar a teoria da dependência para analisar crises ambientais (ROBBINS, 2004). A problemática dos efeitos globais e locais nos esforços de conservação, incluindo locais e biomas de grande diversidade, como as políticas de desenvolvimento e organização espacial da Amazônia (MELLO, 2003; ZHOURI, 2006) e a criação de parques nacionais (FERNANDEZ, 2011), torna-se crescente a partir dos anos de 1990.

A Ecologia Política passa a influenciar direta e indiretamente as pesquisas no Brasil, depois da inserção da problemática ambiental no debate político e nas agendas de pesquisa, da organização dos movimentos indígenas e seringueiros; do surgimento dos movimentos ecologistas e de Organizações Não Governamentais (ONGs). Disso, conclui-se que o ativismo ambiental brasileiro não surgiu do aprimoramento da consciência ecológica, mas da combinação desigual da localização dos impactos ambientais com as possibilidades de soluções tecnológicas acessíveis (MILANI, 2008).

Esse processo é mais bem compreendido quando analisamos os principais programas estatais direcionados para o Cerrado ${ }^{5}$ e para Amazônia Legal ${ }^{6}$, entre os anos de 1960 e 1980, que contribuíram para a marginalização das populações locais, indígenas, ribeirinhos e seringueiros, pois a modernização agrícola regional estimulou a instalação de agricultores oriundos das regiões Sudeste e Sul (PEDROSO e SILVA, 2005), a colonização dirigida e a instalação de infraestrutura de transportes e de energia, que contribuíram para a migração espontânea e para o estabelecimento de grandes projetos agropecuários e de mineração (KOHLHEPP, 2002).

Com a institucionalização de mecanismos de conservação da natureza, nos anos de 1990, que recompensaram os grandes produtores que explorarem de modo sustentável a floresta, inicia-se um processo de criminalização dos indígenas, dos seringueiros e dos ribeirinhos que exploram a floresta (LEROY, 2010). Há o controle do crescimento populacional na medida em que, nas áreas de Floresta Nacional (FLONA) e de Reserva Biológica (REBIO), o movimento dos moradoresé bloqueado 
e a coleta, a caça e a pesca são proibidas (COELHO, CUNHA e WANDERLEY, 2010).

O processo de marginalização das populações tradicionais e locais, em grande medida, é decorrente de ações governamentais que visavam e visam o desenvolvimento econômico regional, terminando por priorizar as elites locais e nacionais. $O$ processo de criminalização, por sua vez, é fruto das ações governamentais e de projetos ambientais que procuram conservar a natureza, restringindo ou limitando o acesso e uso dos recursos naturais. Os projetos do Programa de Aceleração do Crescimento (PAC) combinam as duas dimensões ${ }^{7}$ (MIRANDA, 2011).

\section{Poder, figurações sociais e escalas}

A crescente importância das questões ambientais nas lutas sociais e nas pesquisas que enfatizam amplamente as diferentes relações entre grupos humanos e seus ambientes biofísicos motivou sérias reflexões sobre os conceitos e métodos da Ecologia Política. Alguns ecologistas políticos têm procurado olhar para além da comunidade local, para explicar o acesso e uso de recursos naturais, as práticas de grupos sociais diferenciados pela raça, etnia ou gênero e suas interações cotidianas nos espaços políticos formais (GEZON e PAULSON, 2004; CUNHA, 2004).

Embora a análise das dinâmicas locais seja indispensável, é preciso introduzir o conceito de poder para se apreender os conflitos, referentes à apropriação e uso de recursos naturais, e as mudanças ambientais desencadeadas (GREENBERG, 1994). Nesse sentido, o estudo das relações entre sociedades e naturezas não podem ser apenas reflexões particulares e românticas, como o fazem os ecologistas normativos (GÖRG e BRAND, 2000; GARI, 2000; BELMONTE, 2004), mas uma reflexão que trate o poder enquanto mediador dessas complexas relações (ALIMONDA, 2007).

Ao enfatizar a análise dos processos de tomada de decisão e o contexto social, político e econômico que moldam políticas e práticas ambientais, a Ecologia Política volta sua atenção para a distribuição e controle dos recursos naturais. Em termos metodológicos, é feito o mapeamento das fontes de oposição política aos projetos de modificação da apropriação dos recursos naturais, e parte do pressuposto que os recursos naturais são construídos pela dinâmica de circulação de poder entre os diferentes grupos sociais (CUNHA, 2004).

Ao defender que a mudança ambiental e as condições ecológicas são produto de processos políticos, a Ecologia Política une três suposições fundamentais: (1) a ideia de que os custos e benefícios associados às mudanças ambientais são 
distribuídos desigualmente entre a maioria dos atores; (2) o reforço ou a redução da desigualdade social e econômica existente; e, por fim, (3) as implicações políticas relacionadas às alterações sofridas pelos atores sociais mais afetados com as transformações ambientais (BRYANT e BAILEY, 1997; GROSSMAN, 1998).

Contudo, o controle político e econômico é um processo; nunca está completo e sempre está em mudança, seja no contexto das ideologias, seja no das práticas cotidianas de poder (GEZON, 2004). Apesar da força avassaladora das instituições financeiras internacionais e dos regimes de investimento de capital, as previsões de dominação global nem sempre resultam em formas esperadas de controle político, econômico e em mudanças culturais, como alguns ecologistas políticos associados aos movimentos ambientalistas afirmam.

Os esforços dos ecologistas políticos em incorporar as relações de poder em suas análises não podem ser desconsiderados. No entanto, a maneira como o poder é problematizado torna-o abstrato; não fica explícito quem são os atores sociais que estão ligados aos conflitos e processos de mudança ambiental. Os pesquisadores referem-se a segmentos da sociedade, grandes produtores e populações tradicionais, mas não os apresentam, não destacam quem são os indivíduos que compõem o grupo, as relações de interdependência e as tensões internas.

A adoção da definição de poder de Elias (2001) afasta a Ecologia Política das orientações normativas e fornece as ferramentas teóricas e metodológicas para a investigação das relações socioeconômicas associadas à apropriação de recursos naturais e aos processos de mudança ambiental, pois os indivíduos não são apresentados como seres totalmente fechados em si mesmos, mas como interdependentes, compondo figurações que podem ser observadas e comprovadas empiricamente; podendo, assim, precisar o nascimento e desenvolvimento de figurações específicas.

Em termos analíticos, o estudo de uma figuração não pode ser dissociado das categorias de interdependência, função (compreendido de modo relacional, pois só podemos falar em função quando falamos de interdependências que constrangem pessoas, umas mais outras menos) e coerção (centra-se na compreensão dos condicionamentos que os seres humanos estabelecem mutuamente e nas transformações que sofrem, individualmente ou em grupo, devido ao aumento ou à redução de suas interdependências e às variações de poder) (QUINTANEIRO, 2006).

A apreensão das figurações sociais exige um raciocínio que não se paute em individualidades ligadas umas às outras, mas em termos de relações variáveis entre as posições definidas pelas relações estabelecidas entre indivíduos e/ou 
grupos de indivíduos. Pensar uma figuração é complexificar o processo de dominação, que deixa de ser entendido como uma ação exercida do exterior e numa única direção, de um indivíduo ou grupo sobre o outro, passando a ser concebida pelas relações de interdependência existentes entre fracos e poderosos (HEINICH, 2001).

Os processos de mudança numa figuração são explicados a partir de modelos abrangentes que mapeiem, temporal e espacialmente, as relações sociais, econômicas, políticas e culturais de um grupo ou sociedade, permitindo, assim, a compreensão das relações de interdependência existentes entre os diferentes grupos sociais e no interior destes. Descobertas as interdependências, a identidade última dos indivíduos que formam a figuração pode ser reproduzida:

(...) a determinação das interdependências torna possível preservar totalmente, nos indivíduos de outras sociedades, sua singularidade, sua exclusividade e diferenciação, ao mesmo tempo reconhecendo-os como pessoas em cuja situação podemos nos colocar, ou seja, como homens semelhantes a nós, com os quais estamos ligados por meio de uma identificação última enquanto seres humanos. (ELIAS, 2001, p. 217)

O declínio e a ascensão de um grupo social dentro da figuração são determinados pelas correlações de forças produzidas pelas relações de interdependências entre os diferentes grupos sociais e no interior destes. Quando o balanço de tensões da figuração de indivíduos é alterado, devido às tensões e aos conflitos entre os grupos sociais e entre os membros do grupo, ocorre uma movimentação no interior da figuração (ELIAS, 2001), marcada pela redefinição das posições sociais e dos projetos políticos e econômicos.

Nesse sentido, as formas de dominação são resultantes de lutas sociais que estabilizam, por um determinado momento, a distribuição de poder (ELIAS, 2001). Apesar de o processo de dominação consolidar um modo de partilha do poder, ainda assim haverá um equilíbrio instável de tensões enquanto existir uma interdependência funcional entre as pessoas, mesmo que as diferenças de poder sejam grandes, pois o poder não é como um amuleto, que um indivíduo possui e outro não, é intrínseco às relações humanas, todas elas (ELIAS, 2005).

A noção de poder de Elias $(2001 ; 2005)$ permite à Ecologia Política articular a natureza e a política, sem sobreposições, a partir da análise das relações de interdependência existentes entre os diferentes grupos sociais ${ }^{8}$, locais, regionais, nacionais e internacionais, defensores de estratégias de apropriação de recursos naturais num determinado espaço, que acabam entrando em rota de colisão
8. Para mapear os indivíduos inseridos num determinado espaço usa-se técnicas estatísticas que isolam os grupos sociais para que sejam feitas a caracterização da organização social, econômica e cultural, e a avaliação da distribuição de poder. No entanto, essa separação deve ser temporária porque todos os aspectos de uma figuração social só existem enquanto tais em virtude da posição e função que possuem nela (ELIAS E SCOTSON, 2000). 
9. O termo multiescalar possui variações devido à natureza interdisciplinar do conceito de escalas. As escalas sociais variam do indivíduo, das unidades domésticas, das comunidades, do estado e do global. As escalas ecológicas podem se referir ao indivíduo, à população, aos ecossistemas ou ao planeta. Além disso, as escalas sociais e as ecológicas mostram dimensões temporais diversas (VANWEY, OSTROM E MERETSKY, 2009).
Há pouco tempo, muitos ecologistas políticos enfatizavam apenas uma dessas dimensões, como bem destacam Vayda e Walters (1999) e Latour (2004).

O local e o global no caso da exploração de minério de ferro na Serra de Carajás

Bunker (2007a), ao estudar a exploração de minérios na Serra de Carajás - que redefiniram práticas globais, devido à possibilidade de produção em grande escala, da topografia e da geografia favoráveis ao escoamento da produção, na Amazônia brasileira - ressalta que incorporar o local ao global coerentemente é um grande desafio, sugerindo, portanto, que ao invés de buscar o local no global, é mais importante procurar os modos pelos quais o local pode organizar o sistema mundial.

Para a construção da mina de Carajás, o Brasil realizou o maior empréstimo internacional da história da mineração. Grande parte do dinheiro foi utilizado na construção da ferrovia e do porto. O escoamento do minério de ferro pelo rio Tocantins, a $150 \mathrm{~km}$ a leste da mina, foi descartado pela Companhia Vale do Rio Doce (CVRD), sob influência japonesa e da União Europeia, pois o porto fluvial de Belém (PA) só acomodava navios de 40 e 60 mil toneladas, ao passo que o porto de Ponta da Madeira, em São Luís (MA), recebia navios de mais de 400 mil toneladas, o que justificou a construção de $890 \mathrm{~km}$ de ferrovia na floresta (BUNKER, 2007a).

O processo de exploração de minério de ferro em Carajás implicou em profundas mudanças ambientais devido à instalação da infraestrutura para a extração, processamento e transporte do minério de ferro, e em mudanças socioeconômicas ligadas à chegada de trabalhadores e migrantes em busca de oportunidades e às tensões ocorridas entre os proprietários de terras, agricultores familiares, coletores de castanha-do-pará, índios e a CVRD.

O olhar para o local e suas relações com o global e vice-versa, a fim de compreender os conflitos e os processos de mudança ambiental, abriu caminho para uma Ecologia Política de escalas ou uma Ecologia Política multiescalar ${ }^{9}$, que trata das variações sociais e biofísicas em diferentes níveis de agregação: local, regional, nacional e global. A Ecologia Política de escalas deve ser socialmente construída, relacional e contingente para realçar as faces do poder e dos conflitos oriundos da apropriação de recursos naturais (ZIMMERER e BASSETT, 2003; NEUMANN, 2009).

Nos trabalhos de Jatobá, Cidade e Vargas (2009) e Miranda (2011), o uso das escalas foi fundamental para a compreensão de como as relações sociais, políticas 
e econômicas definem e redefinem aspectos locais e globais e são vetores de processos de mudanças ambientais. No entanto, a adoção das escalas exige alguns cuidados referentes ao papel das relações de interdependência entre os atores e grupos sociais que engendram os processos de mudanças ambientais, nem o local e nem o global devem ser considerados unilateralmente para explicar a problemática socioambiental.

Muitos estudos em Ecologia Política têm incorporado o uso das escalas para compreender as transformações locais decorrentes do estabelecimento de atividades agrícolas ou de mineração, orientadas por estratégias econômicas e políticas, nacionais e internacionais, de exploração de recursos naturais que geram muitos conflitos e fragilizam financeiramente e culturalmente as populações locais e tradicionais (GEZON, 2004; HORNBORG, 2004; PAULSON, 2004; STEVENS, 2004; MIRANDA, 2011).

\section{Processos de territorialização}

Ao trazer para o debate os processos de territorialização, seria insensato não fazer ao menos uma breve discussão sobre esse conceito que vem sendo amplamente utilizado, não só pela Geografia, mas também pela Antropologia e pela Ciência Política (HAESBAERT, 2007). Acrescentaria a essas áreas a Sociologia, a Economia e o próprio Estado brasileiro, que, a partir da Secretaria de Desenvolvimento Territorial (SDT), deu ao conceito uma nova roupagem, procurando associar o território a uma identidade e estratégias produtivas específicas.

Na Geografia, em grande medida, a territorialização é uma realidade produzida pelas relações de classes e pelo lugar social, criando e recriando possibilidades de conquista de parte do território (FERNANDES, 1999); ou a formação de uma agência de recursos materiais e simbólicos capazes de estruturar as práticas de existência de um coletivo social e de informá-lo sobre sua própria identidade (LÉVY e LUSSAULT, 2003). Há também discussões sobre desterritorialização, ou seja, processos de exclusão social e espacial (HAESBAERT, 2007).

A desterritorialização representaria o desaparecimento de territórios em virtude de tragédias naturais ou de disputas entre grupos sociais ou com o Estado, para a redefinição das atividades de um território que termina por deslocar a população. A definição carrega aspectos culturais, que, para a Geografia, são apreendidos a partir das concepções de lugar e de paisagem. Se tratarmos a territorialização como um conceito dinâmico e contínuo, essas mudanças configuram-se como processos de territorialização, e não de desterritorialização.

Na Ciências Sociais brasileira, a Antropologia, talvez por estudar populações 
que procuram se (re)estabeler territorialmente, saiu na dianteira do debate. Para Oliveira (1998, p. 9), o indigenismo e a ação indigenista são formas de territorialização que não podem ser explicadas:

(...) por argumentos e evidências etnohistóricas, nem se reporta apenas às instituições e costumes tradicionais daqueles que sobre ela exercem a sua posse. Seu delineamento ocorre em circunstâncias contemporâneas e concretas, cuja significação precisa ser referida a um quadro sempre relativo de forças e pressões adversas, contrabalançadas por reconhecimento de direitos e suporte político, não correspondendo de modo algum à livre e espontânea expressão da vontade dos membros dessa coletividade. Ademais tal manifestação jamais terá um caráter estático e final, modificando-se segundo os contextos históricos e as conjunturas políticas locais, variando inclusive em suas afirmações internas e de acordo com os diferentes projetos étnicos ali desenvolvidos.

A definição de Oliveira (1998) é abrangente; pauta-se no caráter dinâmico e relacional dos processos sociais que envolvem a institucionalização de áreas indígenas. Almeida (2004) pensa a territorialização enquanto capacidade de organização de grupos sociais em torno de discursos que institucionalizam demandas - os seringueiros, as quebradeiras de coco babaçu e os quilombolas -, voltando seu olhar para o reconhecimento de direitos contestados historicamente e para a habilidade de organização política de grupos sociais em torno de territórios, recursos naturais ou questões étnicas.

Uma característica marcante das proposições antropológicas é a ideia de exclusividade do território para um grupo social, que muitas vezes se redefine, a fim de construir identidades específicas junto aos territórios em formação que reconhecem as disputas entre os diferentes grupos sociais pela apropriação dos recursos naturais, o que não desmerece os trabalhos. Contudo, há o problema de acreditar que não existem tensões dentro do grupo social e que o processo de territorialização termina quando ocorre a aquisição do benefício coletivo.

Para não restringir a territorialização à ocupação social do espaço, como sugerem Mejia e Moreira (2005), a definição de território adotado incorpora as contribuições de Suertegaray $(2001$, p. 6), que vincula ao território a ideia de poder, expressa na apropriação do espaço e seus recursos e na coexistência de grupos, por vezes num mesmo espaço físico em tempos diferentes. Portanto, o território é o local de disputas entre projetos que procuram institucionalizar modelos de apropriação dos recursos naturais dentro de uma figuração social particular, refutando, assim, a tese de que um território seja exclusivo dos grupos sociais locais há muito estabelecidos e de seu uso político pelas Organizações Não Go- 
vernamentais (ONGs), movimentos ambientalistas e órgãos públicos.

Os projetos territoriais são fundamentalmente políticos, pois envolvem atores sociais e instituições que podem defender interesses divergentes e que são orientados por uma atividade econômica dominante, a qual articula outras atividades, atores sociais e ambientes. Sua análise parte de três dimensões: (1) uma relativa às intencionalidades dos atores sociais, que é apresentada na fala dos envolvidos; (2) uma que se refere ao grau de institucionalização dos projetos, percebido no grau de formalização de modelos e estratégias de apropriação dos recursos naturais; e (3) uma dimensão relativa aos diferenciais de legitimação apresentados entre os projetos, referente aos esforços discursivos que dão sentido às intencionalidades (CUNHA, SILVA e NUNES, 2008).

A dimensão institucional pode se referir a um projeto territorial com alto grau de institucionalização, formalmente estabelecido pela legislação vigente, e a projetos territoriais com baixo grau de institucionalização. A dimensão de legitimação também pode se referir a projetos territoriais com alto e baixo grau de legitimação, que se diferem por meio das possibilidades de justificativa discursiva das intencionalidades. Na esfera da legitimação, os discursos podem ser modificados ao longo do tempo, pois refletem disputas de poder entre grupos sociais (CUNHA, SILVA e NUNES, 2008).

Os processos de territorialização são o resultado das tensões entre os diferentes projetos territoriais e estão relacionados às transformações ocorridas numa figuração social específica, mediante a estruturação, desestruturação e reestruturação das formas de controle dos recursos naturais e da organização do espaço, o que decorre das práticas dos grupos sociais interdependentes. Desse modo, os processos de territorialização contemplam as estratégias de produção do espaço, as de reprodução social e as formas de dominação (CUNHA, SILVA e NUNES, 2008).

As origens dos processos de territorialização remetem aos conflitos, às contradições e aos consensos entre os grupos sociais e seus respectivos projetos territoriais, que representam um paralelo entre diferentes poderes e estratégias de gestão e tratam das formas de acesso e uso dos recursos naturais enquanto parte dos processos de conversão de atores sociais (trabalhadores rurais em agriculturas familiares, por exemplo). Não é possível compreender os processos de territorialização sem levar em consideração as dinâmicas constituintes do território. 


\section{Considerações finais}

A problemática ambiental tem estado muito presente nas agendas de pesquisa das últimas duas décadas, em relação à apropriação e uso coletivo de recursos naturais de maneira sustentável e à mitigação dos impactos ambientais por meio da reciclagem e do descarte adequado dos resíduos sólidos, por exemplo. No campo político brasileiro, os debates recentes têm tratado da reformulação do Código Florestal e, consequentemente, das disputas entre ambientalistas e ruralistas, especialmente em torno das áreas de reserva legal.

A Ecologia Política ocupa um lugar de destaque nesse cenário, ao retomar os debates sobre as relações de poder entre os diferentes atores e grupos sociais (locais, regionais, nacionais e internacionais) defensores de projetos territoriais conflitantes. Essas disputas desencadeiam processos de territorialização, constantemente estruturados, desestruturados e reestruturados pelas práticas dos grupos sociais e pelas relações de interdependência estabelecidas, que os ligam uns aos outros pelas redes de interesses referentes à figuração social.

A proposta apresentada permite a compreensão, numa dada figuração social, dos diferentes poderes e estratégias de gestão dos recursos naturais, que acabam sendo os vetores dos conflitos e dos processos de mudança ambiental vividos pelas sociedades contemporâneas. Não é um modelo teórico abstrato que procura enquadrar o objeto de pesquisa numa camisa de força, impossibilitando a compreensão das diferenças locais, regionais e nacionais. Pelo contrário, incorpora os aspectos ambientais, sociais, econômicos, políticos e culturais de modo criativo e relacional.

\section{Referências bibliográficas}

ALIER, J. M. O ecologismo dos pobres: conflitos ambientais e linguagem de valoração. São Paulo: Contexto, 2007.

ALIMONDA, H. "La Ecologia Política de Mariategui: buscando una herencia en Lima”. Tareas, $\mathrm{n}^{\circ} 125,2007$, p. 75-87.

ALMEIDA, A. W. B. "Terras tradicionalmente ocupadas: processos de territorialização e movimentos sociais". Estudos Urbanos e Regionais, vol. 6, n 1, 2004, p. 9-32.

BELMONTE, J. T. "El proceso de monopolización del sistema agroalimentario mundial". Ecología Política, n²8, 2004, p. 61-67.

BIERSACK, A. "Introduction: from the 'new ecology' to the new ecolo- 
gies". American Anthropologist, vol. 101, n 1, 1999, p. 5-18.

BRYANT, R. L.; BAILEY, S. Third world political ecology. New York: Rouyledge, 1997.

BUNKER, S. G. "Os fatores espaciais e materiais da produção e os mercados globais". In COELHO, M. C.; MONTEIRO, M. (org.) A mineração e reestruturação espacial da Amazônia. Belém: NAEA, 2007a.

. "Da castanha-do-pará ao ferro: os múltiplos impactos dos projetos de mineração". In COELHO, M. C.; MONTEIRO, M. (org.) A mineração e reestruturação espacial da Amazônia. Belém: NAEA, 2007b.

CABRAL, L. O. "Revisitando as noções de espaço, lugar, paisagem e território, sob uma perspectiva geográfica". Ciências Humanas, vol. 41, n 1 e 2, 2007, p. 141-155.

COELHO, M. C. N.; CUNHA, L. H.; WANDERLEY, L. J. M. "Conflitos em áreas de mineração na Amazônia: os casos dos quilombolas e dos moradores de beiras de lagos, dos canais fluviais e de estradas em Oriximiná". In ZHOURI, A.; LASCHEFSKI, K. (org.). Desenvolvimento e conflitos ambientais. Belo Horizonte: EDUFMG, 2010.

CUNHA, L. H. Manejo comunitário de recursos naturais na Amazônia: arranjos institucionais e mediação externa. Tese de Doutorado, Universidade Federal do Pará, 2002.

- "Da 'tragédia dos comuns' à Ecologia Política: perspectivas analíticas para o manejo comunitário dos recursos naturais". Raízes, vol. 23, nº 01 e 02, 2004, p. 10-26.

CUNHA, L. H.; SILVA, J. I. A. O.; NUNES, A. M. B. "A proteção da Natureza em assentamentos rurais e nas RPPN's: conflitos ambientais e processos de territorialização". Raízes, vol. 27, n²1, 2008, p. 80-96.

ELIAS, N. O processo civilizador. Rio de Janeiro: Jorge Zahar, 1994.

. A sociedade de corte. Rio de Janeiro: Jorge Zahar, 2001. . Introdução à sociologia. Lisboa: Edições 70, 2005.

ELIAS, N.; SCOTSON, J. L. Os estabelecidos e os outsiders. Rio de janeiro: Jorge Zahar Editor, 2000.

ESCOBAR, A. "O lugar da natureza e a natureza do lugar: globalização ou pós-desenvolvimento?". In LANDER, E. (org.) A colonialidade do saber: eurocen- 
trismo e ciências sociais. Perspectivas latino-americanas. Buenos Aires: CLACSO, 2005.

FERNANDES, B. M. MST: formação e territorialização em São Paulo. 2. ed. São Paulo: HUCITEC, 1999.

FERNANDEZ, A. C. F. "Um rio de florestas: uma reflexão sobre o sentido da criação dos parques na cidade do Rio de Janeiro". Estudos Históricos, vol. 24, n 47, 2011, p. 141-161.

GARÍ, J. A. "La ecología política de la biodiversidad". Ecología Política, n²0:, 2000, p. 15-24.

GEZON, L. L. "Finding the global in the local: environmental struggles in Northern Madagascar". In PAULSON, S.; GEZON, L. L. (eds.). Political ecology across spaces, scales, and social groups. New Brunswick: Rutgers University Press, 2004.

GEZON, L. L.; PAULSON, S. "Place, power, difference: multiscale research the dawn of the twenty-first century". In PAULSON, S.; GEZON, L. L. (eds.) Political ecology across spaces, scales, and social groups. New Brunswick: Rutgers University Press, 2004.

GÖRG, C; BRAND, V. "Política ambiental global y competencia entre estados nacionales: sobre la regulación de la biodiversidad". Ecología Política, n 19, 2000, p. 67-87.

GREenberg, J. B.; PARK, T. K. Political ecology. Journal of Political Ecology, vol. $1, \mathrm{n}^{\circ} 1,1994$, p. 1-12.

GROSSMAN, S. L. The political ecology of bananas: contract farming, peasants, and agrarian change in the Eastern Caribbean. Chapel Hill: University of North Carolina Press, 1998.

HAESBAERT, R. "Concepções de território para entender a desterritorialização". In: SANTOS, M. et al. Território, territórios: ensaios sobre o ordenamento territorial. 3. ed. Rio de Janeiro: Lamparina, 2007.

HARDIN, G. "The tragedy of the commons". Science Magazine, vol. 162, n 3859. 1968, P. $1243-1248$.

HEINICH, N. "Uma sociologia do espaço de interações", In A sociologia de Norbert Elias. Bauru: EDUSC, 2001.

HORNBORG, A. "Undermining modernity: protecting landscapes and meanings among the Mik'maq of Nova Scotia". In PAULSON, S.; GEZON, L. L. (eds.). Political ecology across spaces, scales, and social groups. New Brunswick: Rutgers 
University Press, 2004.

JATOBÁ, S. U. S.; CIDADE, L. C. F.; VARGAS, G. M. "Ecologismo, ambientalismo e Ecologia Política: diferentes visões da sustentabilidade e do território" Sociedade e Estado, vol. 24, 2009, $\mathrm{n}^{\circ}$ 1: 47-87.

KAUTSKY, K. A questão agrária. 3. ed. São Paulo: Proposta Editorial, 1980.

KLINK, F. A. "El fin de la tragedia de los comunes”. Ecología Política, n³, 1992, 137-145.

KOHLHEPP, G. "Conflitos de interesse no ordenamento territorial da Amazônia brasileira". Estudos Avançados, vol. 16, n 45, 2002, p. 37-61.

LATOUR, B. As políticas da natureza: como fazer ciência na democracia. Bauru: EDUSC, 2004.

LEFF, E. "La ecología política en América Latina: un campo en construcción". Sociedade e Estado, vol.18, n²1-2, 2003, p. 17-40.

LEROY, J. P. "Amazônia: território do capital e territórios dos povos". In ZHOURI, A.; LASCHEFSKI, K. (orgs.). Desenvolvimento e conflitos ambientais. Belo Horizonte: EDUFMG, 2010.

LÉVY, J.; LUSSAULT, M. Dictionnaire de la géographie et de l'espace des sociétés. Paris: Belin, 2003.

LIPIETZ, A. A. "A Ecologia Política e o futuro do marxismo". Ambiente \& Sociedade, vol. 5, $n^{\circ} 1 /$ vol. 6, 2003, $n^{\circ}$ 2: 9-22.

LITTLE, P. E. “Ecologia Política como etnografia: uma guia teórica e metodológica". Horizontes Antropológicos, n²5, 2005, p. 85-103.

MEDEIROS, V. B. A. "El movimento de las recolectoras de coco babaçu em Brasil". Ecología Política, n¹1, 1996, p. 169-173.

MEJIA, M. R. G.; MOREIRA, R. J. "Tensões entre diferentes ruralidades na comunidade de Taquari". In MOREIRA, R J.; CARNEIRO, M. J. (orgs.). Identidades sociais: ruralidades no Brasil contemporâneo. Rio de Janeiro: DP\&A, 2005.

MELLO, N. A. "Contradições territoriais: signos do modelo aplicado na Amazônia". Sociedade e Estado, vol. 18, n 1-2, 2003, p. 339-360.

MILANI, C. R. S. "Ecologia Política, movimentos ambientalistas e contestação transnacional na América Latina". Cadernos CRH, vol. 21, n 53, 2008, p. 289303. 
MIRANDA, R. S. Ecologia Política da soja e processos de territorializaçãoda soja no Sul do Maranhão. Tese de Doutorado, Universidade Federal de Campina Grande, 2011.

NEUMANN, R. P. "Political ecology: theorizing scale". Progress in Human Geography Review, vol. 33, n³, 2009, p. 398-406.

OLIVEIRA, J. P. “Apresentação”. In OLIVEIRA, J. P. (org.) Indígenas e territorialização: poder, rotinas e saberes coloniais no Brasil contemporâneo. Rio de Janeiro: Contra Capa, 1998.

OSTROM, E. Governing the commons: the evolution of institutions for collective action. New York: Cambridge University Press, 1990.

. Rules, games, and common-pool resources. Michigan: University of Michigan, 1994.

. "A behavioral approach to the rational choice theory of collective action". American Political Science, vol. 92, 1998, n 01: 1-21.

PAULSON, S. "Gendered practices and landscapes in the Andes: the shape of asymmetrical exchanges". In PAULSON, S.; GEZON, L. L. (eds.) Political ecology across spaces, scales, and social groups. New Brunswick: Rutgers University Press, 2004.

PEDROSO, I. L. P. B.; SILVA, A. P. P. “O papel das políticas públicas no desenvolvimento agroindustrial de Rio Verde-GO”. Caminhos de Geografia, vol. 6, n 15, 2005, p. 20-27.

PORTO, M. F. S. Uma Ecologia Política dos riscos: princípios para integrarmos o local e o global na promoção da saúde e da justiça ambiental. Rio de Janeiro: FIOCRUZ, 2007.

QUINTANEIRO, T. "The concept of figuration or configuration in Norbert Elias' sociological theory". Teoria \& Sociedade, vol. 2, s/e, 2006. Disponível em: $<$ http://socialsciences.scielo.org/pdf/s_tsoc/v2nse/scs_a02.pdf $>$. Acesso em: 23 dez. 2010.

RAFFESTIN, C. Por uma geografia do poder. São Paulo: Ática, 1993.

ROBBINS, P. Political ecology: a critical introduction. Oxford: Blackwell Publishing, 2004.

SANTOS, M. A natureza do espaço: técnica e tempo, razão e emoção. São Paulo: Hucitec, 1999. 
STEVENS, C. J. "Symbolic action and soil fertility: political ecology and the transformation of space and place in Tonga". In PAULSON, S.; GEZON, L. L. (eds.) Political ecology across spaces, scales, and social groups. New Brunswick: Rutgers University Press, 2005.

SUERTEGARAY, D. M. A. "Espacio geográfico uno e múltiplo". Geografía y Ciencias Sociales, vol. 5, n 93, 2001, p. 1-11. Disponível em: <http://www.ub.edu/ geocrit/nova5.htm>. Acesso em: 13 dez. 2010.

VANWEY, L. K.; OSTROM, E.; MERETSKY, V. "Teorias subjacentes ao estudo de interações homem-ambiente". In MORAN, E. F.; OSTROM, E. (orgs.) Ecossistemas florestais: interação homem-sociedade. São Paulo: SENAC, 2009.

VAYDA, A. P.; WALTERS, B. B. "Against political ecology". Human Ecology, vol. 27, $\mathrm{n}^{\circ} 1,1999$, p. 167-179.

WALKER, P. A. "Ecologia Política: onde estão os conteúdos da política”. Desenvolvimento e Meio Ambiente, $\mathrm{n}^{\circ} 24,2011,11-24$.

ZHOURI, A. "O ativismo transnacional pela Amazônia: entre a Ecologia Política e o ambientalismo de resultados". Horizontes Antropológicos, vol. 12, n²5, 2006, p. 139-169.

ZIMMERER, K. S.; BASSETT, T. J. "Approaching political ecology: society, nature, and scale in human-environment studies". In: ZIMMERER, K. S.; BASSET, T. J. (eds.) Political ecology: an integrative approach to geography and environment-development studies. New York: The Guilford Press, 2003. 